\title{
Effectiveness of growth hormone (GH) therapy in children with normal results of GH stimulation tests and with partial GH deficiency is similar and depends on the severity of IGF-I deficiency
}

\author{
Joanna Smyczyńska, Renata Stawerska, Andrzej Lewiński, Maciej Hilczer
}

Department of Endocrinology and Metabolic Diseases, Polish Mother's Memorial Hospital, Research Institute, Medical University of Lodz, Poland; e-mail: endo-iczmp@lodz.home.pl

Disclosure statement: nothing to disclose.

\section{Introduction}

The main goal of growth hormone (GH) therapy in children with short stature is to obtain normal final height (FH). The therapy with recombined human $\mathrm{GH}(\mathrm{rhGH})$ is widely approved in children with short stature and confirmed GH deficiency (GHD). Conversely, in the patients with normal GH peak in stimulation tests, rhGH therapy is still a matter of controversy. On the other hand, the diagnostic accuracy of GH stimulating tests is also discussed. Recently, GHD has been defined as secondary insulin-like growth factor-I (IGF-I) deficiency (IGFD) and it has been proposed to use assessment of growth rate and of IGF-I concentration as a screening procedure in diagnosing GHD. Nevertheless, GH stimulating tests still remain the main procedure that is required to confirm GHD.

The aim of present study was to compare GH therapy effectiveness in the patients with normal results of $\mathrm{GH}$ stimulating tests (normGH) and with isolated partial GHD (pGHD), with respect to IGF-I secretion before treatment.

\section{Patients and methods}

Analysis comprised 257 children (198 boys, 59 girls), age 12.2 \pm 2.8 years (mean \pm SD) with short stature (patients' height below $3^{\text {rd }}$ centile for age and sex, according to national standards for Polish children) in whom GH peak in two GH stimulation tests (with clonidine $-0.15 \mathrm{mg} / \mathrm{m}^{2}$, orally and with glucagon $-30 \mu \mathrm{g} / \mathrm{kg}$ i.m., not exceeding $1.0 \mathrm{mg}$ ) was assessed.

The patients were divided into 2 groups:

normGH -75 patients (56 boys, 19 girls), age $12.1 \pm 2.9$ years, $\mathrm{GH}$ peak $>10 \mathrm{ng} / \mathrm{ml}$

pGHD - 182 patients (142 boys, 40 girls), age $12.3 \pm 2.7$ years, GH peak $5-10 \mathrm{ng} / \mathrm{ml}$

In each patient IGF-I concentration before treatment was assessed. All the patients with normGH and with pGHD were qualified according to IGF-I SDS for age and sex into the following subgroups:

normGH-1 and pGHD-1 - IGF-I SDS <-2.0 (severe IGFD);

normGH-2 and pGHD-2 - IGF-I SDS between -2.0 and -1.0 (partial IGFD);

normGH-3 and pGHD-3 - IGF-I SDS >-1.0 (normal IGF-I secretion - no IGFD).

In all the patients with decreased IGF-I secretion, primary IGFD was excluded by confirmation of significant increase of IGF-I secretion during IGF-I generation test, leading to the conclusion that IGFD in them is non-primary.

All the patients were treated with $\mathrm{GH}$ in the dose of $0.18 \pm 0.02 \mathrm{mg} / \mathrm{kg} /$ week, during $4.9 \pm 2.6$ years, up to the attainment of $\mathrm{FH}$. For each patient the increase of FH SDS with respect to height SDS before treatment ( $\Delta$ HSDS = FH SDS - HoSDS) was calculated.

\section{Results}

The best FH SDS was gained by the groups with the most severe IGFD, i.e. normGH-1 and pGHD-1. The best $\Delta$ HSDS was observed in the same groups, being even better in children with normal GH peak in stimulating tests (normGH-1 group) than in those with decreased GH peak (pGHD-1 group), however the difference between them was insignificant.

The worse $\triangle$ HSDS was observed in the patients with normal GH peak in stimulating tests and normal IGF-I secretion (normGH-3 group). In this group, height gain was below 1.0 SD and the mean FH SDS was below $3^{\text {rd }}$ centile for the age of 18 years and sex.

Similar $\triangle$ HSDS was observed in the groups of children with pGHD and/or less severe IGFD (pGHD-2, pGHD-3 and normGH-2). There was no significant difference in $\triangle$ HSDS between the groups of children with similar IGF-I secretion, despite either normal or decreased $\mathrm{GH}$ peak in stimulating tests, i.e. between normGH-1 and pGHD-1 $(\mathrm{p}=0.42)$, between normGH-2 and pGHD-2 $(p=0.49)$, as well as between normGH-3 and pGHD-3 $(p=0.10)$.

The detailed data are presented in the Table and illustrated in Figure.

\begin{tabular}{|c|c|c|c|c|c|c|}
\hline & \multicolumn{3}{|c|}{ Groups with $\mathrm{GH}$ peak $>10.0 \mathrm{ng} / \mathrm{ml}$} & \multicolumn{3}{|c|}{ Groups with $\mathrm{GH}$ peak 5-10 ng/ml } \\
\hline & $\begin{array}{l}\text { normGH-1 } \\
(\text { IGIII SDS }<-2.0)\end{array}$ & $\begin{array}{c}\text { normGH-2 } \\
\text { (IGF-I SDS - } 2.0 \text { to }-1.0)\end{array}$ & $\begin{array}{l}\text { normGH-3 } \\
\text { (IGF-I SDS }>-1.0)\end{array}$ & $\begin{array}{l}\text { pGHD-1 } \\
\text { (IGI-I SDS <-2.0) }\end{array}$ & $\begin{array}{c}\text { pGHD-2 } \\
\text { (IGF-I SDS - } 2.0 \text { to }-1.0)\end{array}$ & $\begin{array}{l}\text { pGHD-3 } \\
\text { (IGF-I SDS >-1.0) }\end{array}$ \\
\hline $\mathrm{n}$ & 34 & 28 & 13 & 49 & 35 & 98 \\
\hline HoSDS & $-3,22 \pm 0.75$ & $-2.93 \pm 0.61$ & $-3.01 \pm 0.68$ & $-3.00 \pm 0.71$ & $-3.03 \pm 0.90$ & $-3.11 \pm 0.76$ \\
\hline FH SDS & $-1.37 \pm 0.72$ & $-1.50 \pm 1.02$ & $-2.03 \pm 0.88$ & $-1.35 \pm 0.66$ & $-1.74 \pm 0.87$ & $-1.67 \pm 0.80$ \\
\hline$\Delta \mathrm{HSDS}$ & $1.86 \pm 0.93$ & $1.44 \pm 0.77$ & $0.99 \pm 0.71$ & $1.65 \pm 0.89$ & $1.29 \pm 0.77$ & $1.44 \pm 0.92$ \\
\hline
\end{tabular}

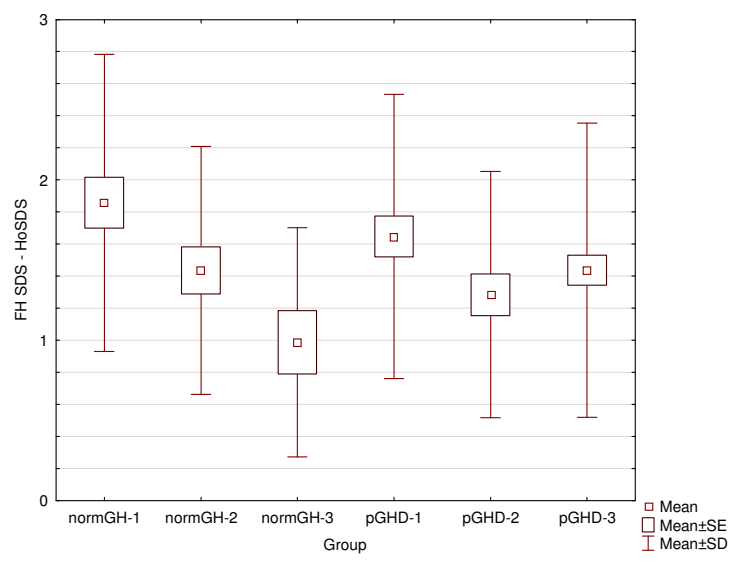

\section{Conclusions}

The effectiveness of rhGH therapy in children with IGFD was independent from the results of GH stimulation tests.

The effectiveness of rhGH therapy in children with normal results of GH stimulation tests was related to IGF-I secretion before treatment, being the best in children with severe IGFD.

The therapy with rhGH should be considered in children with short stature and non-primary IGFD (responding to rhGH administration in generation test), independently from the results of $\mathrm{GH}$ stimulation tests. 